\title{
Crushed EPS in Light weight concrete
}

\author{
Nikita Sharma, Gaurav Suthar, Sayed Aamir Hussain
}

\begin{abstract}
This paper gives light to the ideas of development and implementation of sustainable material to reduce the reliance on non-renewable resources which can be achieved by using light weight concrete in construction as the demand of light weight concrete is growing day by day. The availability of light weight aggregates and admixtures has made this approach easy. Expanded polystyrene (EPS) is a material used for packaging of various products. Due to its voluminous, bulky nature and being non-biodegradable it has high resistivity towards chemical reactions so its disposal is an issue also when disposed in landfills it covers more space. This paper promotes the use of EPS in light weight concrete structures. Expanded Polystyrene concrete is used in modern applications such as thermally insulated partition walls, exterior walls, members of floating structures and deck of bridges. This work comprises of casting and testing of light weight concrete with EPS as an aggregate, fly ash as finer including sulphonated naphthalene (SN) based admixtures. A canoe is also designed and tested for floating capacity. The percentage ratio of EPS to cement is trialed between (0.25-0.3) by weight percent. As per IS 456-2000 clause 15-17 [1] testing light weight concrete cubes and after evaluating six different compositions, the optimum ratio was adopted.
\end{abstract}

Keywords: Expanded Polystyrene EPS, fly ash, light weight concrete, sulphonated naphthalene admixtures.

\section{INTRODUCTION}

In everyday life due to high consumption of resources such as coarse aggregates and fine aggregates, these resources are depleting day by day therefore there is an urgent need to conserve these natural resources by developing new eco-friendly technologies and thereby managing the available resources at the places highly necessary. One such technology is the use of light weight concrete for structural as well as non-structural purpose like partition walls, members of floating structures, thermally insulated partition walls, sideways. The light weight concrete containing EPS as aggregate can easily be used for such purpose.

Rather than recycling the EPS from the packaging materials can be crushed into small pieces and then, can be used in the form of aggregates in light weight concrete

Revised Manuscript Received on March 5, 2020.

Nikita Sharma*, Techno India NJR Institute of Technology Udaipur 313001.sharma.nikita6609@gmail.com

Gaurav Suthar, Techno India NJR Institute of Technology Udaipur 313001

Sayed Aamir Hussain, Techno India NJR Institute of Technology Udaipur 313001 e use of this light weight concrete requires no sand and coarse aggregate which thereby reduces the depletion of such natural resources. Therefore, using EPS as aggregate can be a proper substitution for fulfilling the needs of the construction industry as well as conserving such natural resources.

\section{LITERATURE REVIEW}

Light weight concrete refers to type of concrete mix which comprises of light weight and low density aggregates i.e. increasing the volume of mix simultaneously providing considerable decrement in self-weight and dead loads. The

key point of attraction in light weight concrete is its low density and thermal conductivity as formation of voids with air entrapping takes place because of low density high volume aggregates. Compressive strength shows directly proportional relationship with density of the mix as for less densified mix, compressive strength decreases and vice-versa. Though light weight concrete has less compressive strength as compared to standard commercial concrete, but increasing compressive strength achievement trends the light weight concrete in structural construction industry. As strength can be increased by densification of mix and by addition of superplastizers hence, light weight concrete can be used in both structural and non-structural applications.[2]

Various engineering properties of concrete differ with the addition of crushed EPS. The relation between the quantity of eps added and workability of concrete mix is inversely proportional i.e. with the increment in amount of EPS the provided surface area increases and hence workability reduces ensuring the requirement of superplasticizers. Due to low density of eps aggregates, the unit weight of the light weight concrete mix decreases. As density, compressive strength, strain(elastic) and modulus of elasticity are the functions of unit weight therefore these values also decreases with the increase in quantity of EPS. Also creep increases with significant increase in EPS.[3]

Density of the light weight concrete containing expanded polystyrene as aggregate depends on its ratio of aggregate and cement hence using the crushed waste EPS in light weight concrete increases the density and flow ability of mix as compared to EPS beads. With the increase in EPS percentage added to mix the thermal conductivity decreases gradually. So on optimization of added crushed EPS quantity and density of mix leads to the unfolding of material for not only heat insulation, but also for thermal insulation in structural aspect.

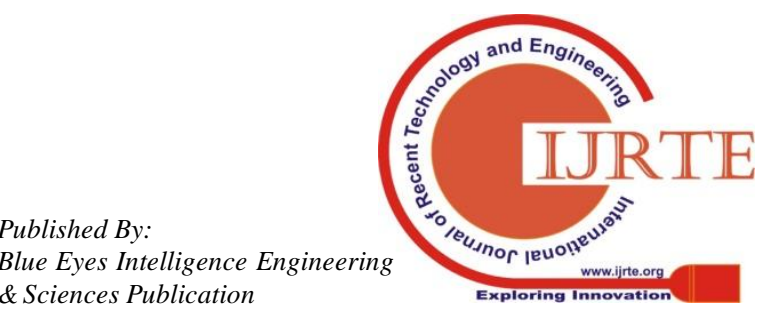




\section{Crushed EPS in Light weight concrete}

Many challenges towards building energy conservation can be solved by using the light weight concrete containing EPS by enhancing the thermal characteristics of structural elements specially which are at outer face of structures. [4]

The materials included in designing and construction of canoe are polystyrene beads, perlite, sand and cement. After partial replacement of sand with $50 \%$ polystyrene $50 \%$ perlite makes the mix appropriate for making of canoe. Canoe made from this finalized proportion floats well on the surface of surface. With the increase in polystyrene percentage added in the mix composition, the percentage of water absorption increases.[5]

\section{MATERIAL PROPERTIES}

\section{A. Cement}

Ultratech OPC 'ordinary Portland cement' grade 53 is used as a binding material. It has initial setting time of 30 minutes and final setting time of 600 minutes.

TABLE-1: Composition of Ordinary Portland Cement and Fly Ash

\begin{tabular}{|c|c|c|}
\hline OXIDE & $\begin{array}{c}\text { Cement } \\
\text { content } \\
\text { (per cent) }\end{array}$ & $\begin{array}{c}\text { Fly Ash } \\
\text { content } \\
\text { (per cent) }\end{array}$ \\
\hline $\mathrm{CaO}$ & $65-67$ & 1.20 \\
\hline $\mathrm{SiO}_{2}$ & $21-25$ & 18.5 \\
\hline $\mathrm{Fe}_{2} \mathrm{O}_{3}$ & $0.5-0.6$ & 10.5 \\
\hline $\mathrm{Al}_{2} \mathrm{O}_{3}$ & $4.0-8.0$ & 15.3 \\
\hline $\mathrm{K}_{2} \mathrm{O}$ & $0.2-0.6$ & 2.21 \\
\hline $\mathrm{MgO}$ & $0.1-4.0$ & 0.3 \\
\hline $\mathrm{Na}_{2} \mathrm{O}$ & $0.2-0.6$ & 0.988 \\
\hline $\mathrm{SO} 3$ & $1.3-3.0$ & 0.35 \\
\hline
\end{tabular}

\section{B. Fly Ash}

Fly Ash is finely divided residue resulting from the combustion of powdered coal. Initially Fly ash was considered as a waste and due to dumping it chocking of rivers has taken place in the southern India regions but now in

the modern concrete Fly ash is an essential ingredient and its use in concrete helps in prevention of environmental pollution.

The spherical form of particles improves the flow ability and reduces the water demand. Fly ash in concrete increases the strength of concrete due to pozzolanic reactivity in the presence of moisture thereby developing greater strength at the later stage. It also decreases water permeability and gas permeability.

\section{EPS - Expanded Polystyrene}

This is a super lightweight, repetitive units of styrene polymer having tiny channels developed in structure during the manufacturing process. Due to its good thermal insulation properties and shock absorption nature it's plastic form is normally used in packaging of heavy goods and insulation panels.

EPS is one of the cellular plastic which can be found in the different shapes. It is used for packing televisions, refrigerators and other heavy materials, so that they can be transported safely without any damage. It has high mechanical resistance and is recyclable. Due to all these characteristics EPS is gaining attraction in market and in construction industry also.

Long EPS sheets and blocks were crushed into small pieces by use of brush with metal teethes and sieved by $4.75 \mathrm{~mm}$ IS sieve.

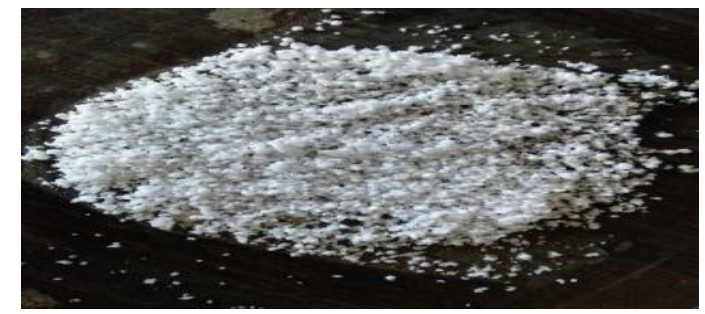

Fig. 1. Crushed EPS

\section{Admixtures}

Cement used has initial setting time of 30 minutes, simultaneously EPS has light weight and large volume combination so in order to prevent segregation, proper mixing is necessary. Proper mixing takes time so initial setting time of cement is delayed by adding chloride free sulphonated naphthalene-SN based retarder type admixture by slowing down the chemical reaction of hydration of concrete and increasing its workability.

$\mathrm{SN}$ based admixture[6] reduces the required water content playing role of water reducer hence densifying the mixture and helps in achieving good compressive strength. The relative density and $\mathrm{pH}$ is equal to $1.10 \mathrm{~kg} / \mathrm{l}$ at $25^{\circ} \mathrm{C}, \geq 6$ respectively. By electrostatic force of repulsion, it develops a negative charge on cement particles and disperse them hence enables the water content of the mixture to perform more effectively.

In addition, with $\mathrm{SN}$ based admixture a Naphthalene based superplasticizer is also added to mixture in order to gain higher density, higher strength and reduced permeability.

\section{PROPORTIONS ADOPTED}

\section{A. Water Cement Ratio}

Water Cement ratio is given by weight of water divided by the weight of cement in a mix. Strength of concrete depends upon the dilution of mixture as it increases with cement content and decreases with air and water content. Hence, value for water to cement ratio is trailed between 0.26-0.3. After sufficient trails value for this governing ratio is finalized as 0.26 ,

$$
x=\frac{w}{c}
$$

Where, ' $w$ ' is weight of water

$$
\text { ' } c \text { ' is weight of cement }
$$

\section{Percentage ratio of EPS to Cement by weight}

A governing percentage ratio of EPS to Cement $(\varnothing)$ is introduced to balance to the quantity of EPS as it has low weight and large volume. Range is adopted between 2.0 to 4.0 


$$
\emptyset=\frac{\text { EPS }}{\text { Cament }} \times 100
$$

After several trials for different quantities of EPS and cement the finalized of ' $\varnothing$ ' is taken as 2.53 .

\section{SAMPLE PREPARATON AND TESTING}

Different types of 6 compositions are prepared and 3 cubes are casted for each composition. Moulds for cubes of size $100 \mathrm{~mm} \times 100 \mathrm{~mm} \times 100 \mathrm{~mm}$ are casted in 3 layers with each layer being tampered 25 times followed by oiling of inner surface of moulds in order to obtain the homogenous and smooth finished surface. After 24 hours the cubes are demolded and cured. 2 cubes from each composition were tested after 3 days in Universal Testing Machine for 3-day compressive strength while one cube from each composition was tested after 7 days in Universal Testing Machine to get 7-day compressive strength.

Cubes are tested under the IS 456-2000[1] guidelines with application of gradual loading and different values are noted as shown in table 2 .

To examine the low density as well as high compressive strength of the light weight concrete some floating parameters must be adopted. For this purpose, a canoe was designed and casted for the optimum composition.

The canoe has dimensions of length, breath, height, thickness as $425 \mathrm{~mm}, 215 \mathrm{~mm}, 155 \mathrm{~mm}, 25 \mathrm{~mm}$ respectively.

For this a wooden mold is designed and given the shape a canoe, the concrete mix is designed for the finalized proportion and filled in the mould this is allowed to settle for 7 days along with curing by damp cloth.

The canoe is then demolded and kept on water surface for checking its floating capacity. After this, it is tested for the amount of load it can bear without sinking. It is seen that a $5.73 \mathrm{~kg}$ canoe can bear load of about $12 \mathrm{~kg}$ load and the top edge at stern was noted $7.5 \mathrm{~cm}$ above the water surface. By the above observation it can be concluded that the canoe floats due good volume of air entrapping, buoyant force and low density of mix i.e. half the density of standard concrete. Therefore, this composition can be used for construction the members of floating structures also.

Due to good quantity of EPS its thermal resistance also increases.

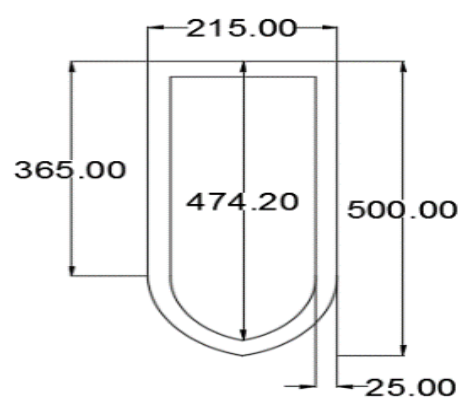

Fig. 2. Dimensions of Canoe (in mm)

\section{RESULT}

The load bearing strength of light weight concrete using EPS are given in the table for all the 6 compositions. Fly Ash is used to increase compressive strength simultaneously it increases workability of the mix. Various compressive strengths are noted as mentioned in table 2

For the sample S1 and S2 the strength of concrete cube increases with increase in fly ash content at constant water cement ratio and $\varnothing$, but after testing the failure surface was found to be non-homogenous. For S3 and S4 with increase in fly ash and water cement ratio and slight increase in $\varnothing$, the strength increases more.

By this result it can be seen that the strength is increasing with increase in workability and homogeneity. To increase the strength furthermore, the SN based retarder is added to increase the workability and homogeneity of the mix. The concrete becomes homogenous but after demolding of the cubes it is seen that due to high workability of mix and less density of EPS, the concrete mix develops segregation. The EPS being light weight acquires the upper positon in the sample cube while the fly ash and cement having high density have settled at the bottom. Hereby the strength of the sample decreases.

After all these observations the amount of $\mathrm{SN}$ based Admixtures is kept constant while the water cement ratio is reduced to 0.26 . Also to reduce the overall density of concrete the fly ash content is also reduced from $20 \%$ to $13.5 \%$. The value of ' $\varnothing$ ' is reduced by small percentage from $2.6 \%$ to $2.53 \%$. At this composition the cubes attain the good strength of about $1.7 \mathrm{MPa}$ in 3 days and $5 \mathrm{MPa}$ in 7 days. The failure surface is homogenous and the density of the concrete mix is found to be $1310 \mathrm{~kg} / \mathrm{m}^{3}$, this optimum ratio is finalized.

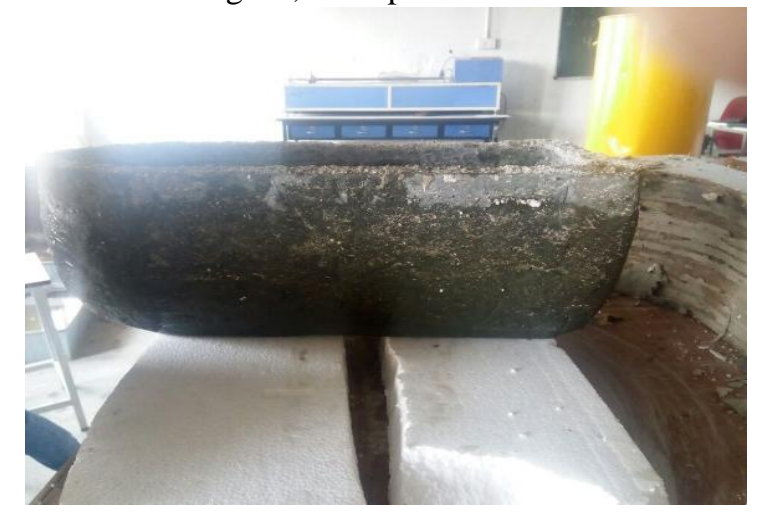

Fig. 3. Casted Canoe

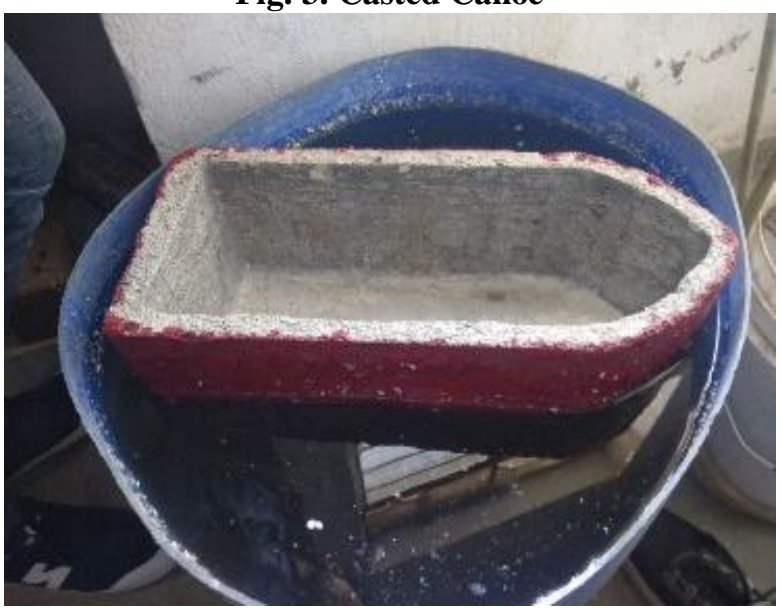

Fig. 4. Floating Canoe

Published By:

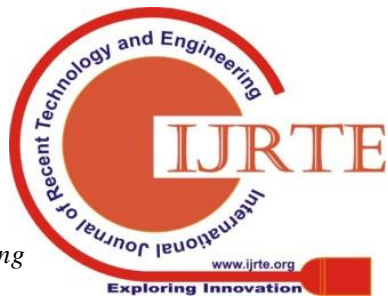




\section{Crushed EPS in Light weight concrete}

Table- II: Average 3 and 7 day Compressive strengths of different mix proportions

\begin{tabular}{|c|c|c|c|c|c|c|c|c|}
\hline Sample & $\begin{array}{c}\varnothing \\
(\%)\end{array}$ & $\begin{array}{c}\text { Fly ash } \\
(\%)\end{array}$ & $\mathrm{W} / \mathrm{C}$ & $\begin{array}{c}\text { Ad.- SN } \\
\text { based } \\
\text { (ml per } \mathrm{Kg} \\
\text { of cement) }\end{array}$ & $\begin{array}{l}\text { Naphthalene } \\
\text { superplasticizer } \\
\text { (ml per Kg of } \\
\text { Cement) }\end{array}$ & $\begin{array}{l}\text { ACS } \\
3 \text { day } \\
\text { (MPa) }\end{array}$ & $\begin{array}{l}\text { ACS } \\
7 \text { day } \\
\text { (MPa) }\end{array}$ & $\begin{array}{c}\text { Weight of } \\
\text { cube } \\
\text { (grams) }\end{array}$ \\
\hline S1 & 2.55 & 8 & 0.26 & - & 9 & 0.68 & 1.9 & 1028 \\
\hline S2 & 2.55 & 10 & 0.26 & - & 9.5 & 0.77 & 2.3 & 1189 \\
\hline S3 & 2.6 & 17 & 0.3 & - & 10 & 0.82 & 2.52 & 1301 \\
\hline S4 & 2.8 & 20 & 0.3 & - & 10 & 0.9 & 2.61 & 1289 \\
\hline S5 & 2.6 & 20 & 0.3 & 8 & 10 & 1.15 & 3.4 & 1255 \\
\hline S6 & 2.53 & 13.5 & 0.26 & 8 & 10 & 1.7 & 5 & 1309.8 \\
\hline
\end{tabular}

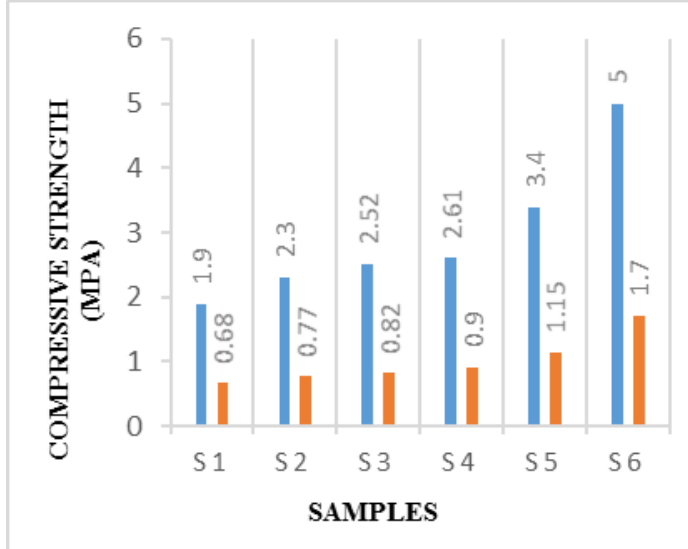

Fig 5. - Average compressive strength comparison

\section{DISCUSSION}

Different mechanical and physical properties are affected with different concrete mix design for the light weight concrete containing EPS. The amount of EPS taken changes the density, strength and thermal properties of concrete for samples with different percentage of fly ash, different cases were observed with increase in fly ash content, the density increases and simultaneously strength increases. However, after the addition of $\mathrm{SN}$ based admixtures the strength increases even at lower percentage of fly ash content, thereby giving good strength with low density. This low density of concrete mix approximately half the density of normal concrete is responsible for the floating of the canoe. As canoe takes two times the load of its self-weight hence it shows the considerable contribution of low density along with volume entrapping.

\section{CONCLUSION}

- The properties of light weight concrete alter with different water-cement ratio, $\varnothing$ and admixtures.

- The compressive strength of the samples of light weight concrete with EPS varies from 1.9MPa to $5 \mathrm{MPa}$ (7 days).

- The light weight concrete has floating properties has the canoe designed can take the load of about $12 \mathrm{~kg}$.

- The insulation property increases with increases in the quantity EPS and vice-versa.
- EPS can be used as a replacement of coarse aggregate.

- Relation between quantity of EPS and compressive strength is inversely proportional, and same as for density.

- The brushed EPS provides more workability due to the its shape and surface condition.

- When the SN based admixture is added, the homogeneity and the workability increase while segregation and required water content reduces.

\section{REFERENCES}

1. IS 456, "Concrete, Plain and Reinforced," Bur. Indian Stand. Dehli, pp. $1-114,2000$.

2. "study of light weight concrete behaviour."

3. Hjh Kamsiah Mohd.Ismail(Head) Mohamad Shazli Fathi Norpadzlihatun bte ManafB. Sabaa and R. S. Ravindrarajah, "Engineering Properties of Lightweight Concrete," Symp. MM Adv. Mater. Cem. Compos., no. August 2015, pp. 1-11, 1997."Polystyrene concrete as the structural thermal insulating material."Makhmud Kharun, Alexander P. Svintsov

4. "experimental study of light weight concrete."

5. Dr. Eethar Thanon Dawood

6. S. O. Osuji and D. Ikogho, "Current Effects of Naphthalene Based Superplasticizer' s Addition Process on Water Reduction and Grade C20 / 25 Concrete 's Compressive Strength," vol. 8, no. 1, pp. 9-14 2018, doi: 10.5923/j.jce.20180801.02.

\section{AUTHOR PROFILE}

Nikita Sharma IV year civil engineering. student from Techno India NJR Institute of Technology, Udaipur. ' 1 st runner Up Bentley Student design challenge 2018,

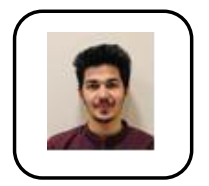

Gaurav Suthar IV year civil engineering. student from Techno India NJR Institute of Technology, Udaipur. ' 1 st runner Up Smart India Hackathon 2018'.

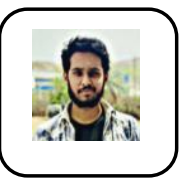

Sayed Aamir Hussain IV year civil engineering. student from Techno India NJR Institute of Technology, Udaipur. ' $1{ }^{\text {st }}$ runner Up Smart India Hackathon 2018' 